\title{
Paraguay 2017: competencia política en las Cámaras, EN LAS CALLES Y EN LAS URNAS
}

\author{
Paraguay 2017: Political Competition in the Legislature, \\ in the Streets and in the Ballot Box
}

\author{
ANDRÉS CARRIZOSA \\ Rice University, Estados Unidos
}

\section{RESUMEN}

En el año 2017, la política paraguaya estuvo dominada por dos eventos centrales: 1) el intento de modificación de la Constitución para permitir la reelección, y 2) las internas partidarias con miras a elecciones generales de 2018. Finalmente, la enmienda para permitir la reelección no fue aprobada pero el costo de los procesos informales fue la destrucción del edificio del Congreso y la muerte de una persona. En contrapartida, las mismas facciones políticas que compitieron por la reelección lo hicieron en las internas partidarias en un proceso pacífico y organizado. Proveyendo un resumen de los eventos políticos, sociales y económicos del Paraguay en 2017, este artículo sugiere que los procesos institucionalizados permiten la resolución de conflictos políticos de una manera constructiva.

Palabras clave: Paraguay, internas, liberales, colorados, elecciones

\begin{abstract}
Paraguayan politics in 2017 was dominated by two central events: 1) the attempt to modify the constitution to allow for presidential reelection, and 2) party primaries in anticipation of the 2018 general elections. The amendment to allow for reelection was not approved, but the informal procedures through which it was advanced resulted in the destruction of the Congress building and the loss of a life. On the other hand, the same factions that competed over the reelection amendment also competed in the party primaries but in an organized and peaceful manner. By summarizing the main political, social and economic events that happened in Paraguay in 2017, this article suggests that institutionalized processes allow for the resolution of conflicts in a more constructive way.
\end{abstract}

Keywords: Paraguay, primaries, liberals, colorados, elections 


\section{INTRODUCCIÓN}

En el año 2017 la política paraguaya estuvo dominada por dos eventos centrales: 1) el intento de modificación de la Constitución para permitir la reelección presidencial, y 2) las internas partidarias. Aunque estas disputas venían en crecimiento desde el año 2016 (González Bozzolasco 2017), los conflictos que rodearon la modificación de la Constitución para permitir la reelección realmente estallaron en el 2017. Eventualmente, los políticos opositores, la ciudadanía movilizada, y organizaciones internacionales se unieron para impedir la reelección, pero los costos de este conflicto fueron altos. Como resultado de las disputas, manifestantes quemaron el edificio del Congreso Nacional. También, la policía nacional hirió gravemente a un diputado con balas de goma (Edgar Acosta), e hirió de muerte al funcionario partidario Rodrigo Quintana —ambos del Partido Liberal.

Tras el entierro definitivo del proyecto de enmienda, el 27 de abril de 2017, las competencias políticas se tornaron en conflictos internos dentro de cada partido. El proyecto de enmienda había dividido a los dos partidos más grandes -el Partido Colorado (Asociación Nacional Republicana, ANR) y el Partido Liberal (Partido Liberal Radical Auténtico, PLRA) - en facciones pro y antienmienda, y estas mismas facciones internas fueron las que compitieron por controlar las nominaciones de sus respectivos partidos. Finalmente, el año terminó con la elección de Mario Abdo Benítez como candidato a presidente por la ANR y de Efraín Alegre como candidato a presidente por el PLRA. Ambos candidatos estuvieron en contra del proyecto reeleccionista, y ambos fueron antagónicos al presidente Horacio Cartes en el pasado.

La mayor parte de este artículo se dedicará a discutir la crisis de la enmienda, cómo la resolución de esta crisis creó el escenario para las elecciones internas, y los resultados de las internas partidarias. Aunque el enfoque será principalmente sobre política, este texto también analizará brevemente la situación económica del país. Finalmente, el ensayo concluye discutiendo los desafíos que 2017 dejó para el año 2018.

\section{CRISIS DE LA ENMIENDA}

La primera mitad del año 2017 estuvo dominada por el intento del presidente Cartes y de sus aliados de modificar la Constitución para permitir la reelección presidencial. Para entender detalladamente cómo se desenlazó la crisis de la enmienda, es necesario entender las leyes paraguayas y las facciones políticas en competencia. Parte de esta discusión ya fue analizada (González Bozzolasco 2017). Sin embargo, la crisis de la enmienda fue de tal importancia para la historia política del Paraguay, que cualquier recuento de los hechos de 2017 estaría incompleto sin tratar este tema en detalle. En las siguientes subsecciones se analizan las instituciones formales del Paraguay, las facciones políticas 
en competencia y las estrategias que estas facciones políticas utilizaron para avanzar en sus intereses. La sección termina discutiendo el apogeo de la crisis de la enmienda y la resolución final de dicha crisis.

\section{Instituciones formales}

Los mecanismos existentes para modificar la Constitución ya fueron explicados detalladamente (González Bozzolasco 2017), pero para dar al lector un recuento completo lo discutiré brevemente. En resumen, hay dos formas de modificar la Constitución: la reforma y la enmienda. La reforma tiene umbrales más altos — de dos tercios de cada cámara - para ser aprobada, y requiere la elección de una convención constituyente para reescribir la Constitución completamente (Constitución Nacional 1992, Art. 289). La enmienda solo requiere una mayoría absoluta $-50 \%+1$ de todos los legisladores de cada cámara, no sólo de los presentes- y posteriormente se tiene que llevar a cabo un referendo para aprobarla o rechazarla. Habiendo dicho eso, la Constitución establece que la enmienda no se puede utilizar para modificar varios capítulos de ella — como el Capítulo II, que establece que el presidente y vicepresidente "no podrán ser reelectos en ningún caso" (Constitución Nacional 1992, Art. 299). Finalmente, la Constitución también establece que si la enmienda fracasa, el mismo proyecto de enmienda no puede tratarse nuevamente hasta cumplido un año de su rechazo (Constitución Nacional 1992, Art. 290). ${ }^{1}$

A pesar de esas disposiciones constitucionales, la facción prorreelección intentó modificar la Constitución utilizando una enmienda para evitar el proceso más difícil de la reforma constitucional. Esto fue en parte porque no tenían el apoyo suficiente para superar los umbrales de la reforma, pero también porque la cercanía de las internas partidarias obligaba a los reeleccionistas a apurarse para poder habilitar al Presidente Cartes como candidato en las internas. La modificación de la Constitución para permitir la reelección utilizando la enmienda en vez de la reforma ya fue intentada en el pasado, sin éxito, por el expresidente Nicanor Duarte Frutos (Abente Brun 2007; González Bozzolasco 2017) y Fernando Lugo (Abente Brun 2012).

\section{Facciones políticas}

Las coaliciones a favor y en contra de la enmienda constitucional dividieron a los partidos tradicionales internamente (González Bozzolasco 2017). Dentro del Partido Colorado, el presidente Horacio Cartes y el presidente del mismo partido Pedro Alliana estaban a favor de la enmienda. Los opositores colorados estaban liderados por Mario Abdo Benítez — senador colorado y anterior

Ver Turner (2010: 444-448) para un resumen de la estructura y el funcionamiento de los poderes del Estado paraguayo. 
vicepresidente del partido. Aunque las divisiones fueron agravadas por el conflicto sobre la enmienda, estas facciones ya habían empezado a existir en 2015, cuando Abdo compitió, y perdió, contra Alliana por la presidencia del Partido Colorado (Última Hora 2015). En pocas palabras, el Partido Colorado estaba dividido entre el movimiento "Honor Colorado", formado alrededor de Cartes y Alliana, y el movimiento "Añetete", formado alrededor de la figura de Abdo - con un movimiento apoyando y el otro intentando detener la enmienda, respectivamente.

El Partido Liberal también estuvo dividido internamente con relación a la enmienda reeleccionista (González Bozzolasco 2017). Por un lado, Efraín Alegre — candidato presidencial en el 2013 y presidente del Partido Liberal desde el 2016 - lideraba la oposición a la enmienda. Por otro lado, Blas Llano, expresidente del partido liberal hasta su renuncia en mayo de 2013, lideraba el apoyo a la enmienda (Abc Color 2013). Estos dos actores también compitieron electoralmente en el pasado. En el 2012, con miras a las elecciones presidenciales de 2013, Efraín Alegre y Blas Llano compitieron por la candidatura presidencial del Partido Liberal. Efraín Alegre finalmente ganó, pero los resultados de las "urnas delivery" que se llevaron a cabo en vez de unas internas convencionales fueron fuertemente disputados por Llano y Alegre (Abc Color 2012; Última Hora 2012; Abente Brun 2012; Duarte Recalde 2013). Secuelas de esta animosidad también se vieron en el 2017 durante la convención liberal, donde Alegre consiguió que el Partido Liberal tome una postura institucional en contra de la reelección, aprobando sanciones contra los legisladores que votaran a favor de la enmienda. La convención fue muy polémica, y terminó con los convencionales peleándose a golpes y tirándose sillas de plástico (Abc Color 2017a). En resumidas cuentas, el Partido Liberal también estaba dividido internamente con Blas Llano y el movimiento “Equipo Joven" apoyando la reelección presidencial y Efraín Alegre y una coalición de movimientos liberales trabajando en contra de la reelección.

Los demás partidos no-tradicionales no tenían divisiones internas, pero algunos favorecían la enmienda constitucional. Notablemente el Frente Guasu, liderado por Fernando Lugo-senador y ex-presidente quien fue removido con un juicio político en el 2012 (Duarte Recalde 2013) — apoyaba el proyecto de enmienda ya que su aprobación habilitaría a Lugo a candidatarse de vuelta. Los demás partidos que conforman "la izquierda" y que tenían representación en el Senado, como el Avanza País (AP), el Partido Demócrata Progresista (PDP), y el Partido Encuentro Nacional (PEN), estaban en contra de la enmienda. En ese sentido entonces, la izquierda paraguaya estaba dividida en relación a la reelección presidencial, pero a diferencia de los partidos tradicionales esta división era una división inter-, y no intra-partidaria. Finalmente, la UNACE, un movimiento interno del Partido Colorado que se volvió un partido político independiente bajo el liderazgo de Lino Oviedo, pero que perdió fuerza después de la muerte de Oviedo en 2013 (Turner 2014), también apoyaba el proyecto reeleccionista. 


\section{Maniobras institucionales de las diferentes facciones}

La mayor dificultad para la aprobación de la enmienda seencontraba en la Cámara de Senadores por tres razones principales. La primera razón es porque el 25 de agosto de 2016 el Senado trató y rechazó el proyecto de enmienda constitucional para permitir la reelección presidencial. Como mencioné anteriormente, un proyecto de enmienda que no prospera no puede ser tratado de vuelta por un año, entonces los opositores a la enmienda hicieron esto en un momento que el ejecutivo no estaba prestando atención para eliminar la posibilidad de debatir la enmienda hasta el 25 de agosto de 2017 (Abc Color 2016; González Bozzolasco 2017). Esto se volvió una barrera muy grande para el Presidente Cartes dado que el Tribunal Superior de Justicia Electoral (TSJE) anunció que cualquier enmienda tendría que ser aprobada antes del 22 de agosto de 2017, porque de ser aprobada después de esa fecha el TSJE no tendría la capacidad de llevar a cabo el referendo necesario antes de las internas partidarias (Abc Color 2017b). Imponer la enmienda, entonces, también requeriría violar esta disposición constitucional para alcanzar el plazo impuesto por el TSJE.

La segunda razón por la cual el Senado fue la barrera más importante era porque el Presidente de la Cámara de Senadores Robert Acevedo, PLRA, estaba en contra de la reelección presidencial (González Bozzolasco 2017: 554 y 558). Acevedo, y el Vicepresidente Primero del Senado Eduardo Petta, PEN, estaban utilizando las atribuciones de sus cargos para evitar dar entrada al proyecto de enmienda. Por ejemplo, el 27 de marzo de 2017 once senadores - colorados, liberales y del Frente Guasu - enviaron una carta al presidente del Senado pidiendo una sesión extraordinaria, y Acevedo utilizó sus atribuciones para rechazar el pedido de sesión argumentando que no se cumplieron los requisitos formales para la sesión extra (Abc Color 2017c; Abc Color 2017f). Buscando socavar a Acevedo, los reeleccionistas querían esta sesión extra para modificar dos artículos del reglamento interno de la Cámara de Senadores: el Artículo 41 Inciso II, que permite al presidente del Senado retener proyectos, y el Artículo 119 que establece que una moción presentada para estudiar un proyecto que no tenga dictamen de comisión requiere una mayoría de dos tercios para ser considerada en el pleno (Abc Color 2017d). Como la remoción del presidente del Senado no está contemplada en el reglamento interno de la Cámara de Senadores, los reeleccionistas prefirieron enfocarse en quitarle sus atribuciones (Última Hora 2017a). En contrapartida, los opositores de la enmienda buscaban explotar las atribuciones del presidente del Senado para aplazar dar entrada al proyecto, y luego alargar lo más posible el estudio del proyecto de enmienda en comisión - proceso que puede durar meses.

Finalmente, la tercera razón por la cual el Senado era la barrera más importante fue por la ausencia del poderjudicial durante todo este proceso. La CorteSuprema pudo haber aclarado la vía constitucional por la cual se tenía que modificar la Constitución y pudo haber aclarado si era constitucional que el Senado tratase un mismo proyecto de enmienda en menos de un año. En general, la Corte 
Suprema no intervino en esta crisis constitucional, y de haberse aprobado la enmienda para permitir la reelección la probabilidad de que la Corte Suprema declare la inconstitucionalidad de esa enmienda hubiese sido muy baja. A causa de esto, los conflictos constitucionales y legales se tuvieron que resolver con fuerza bruta política más que por procedimientos institucionalizados.

\section{Apogeo de la crisis}

El 28 de marzo de 2017 el vicepresidente segundo del Senado Julio César Velázquez (ANR) usurpó las facultades del presidente del Senado y dio entrada al proyecto de modificación del reglamento interno de dicha cámara. El hecho fue ilegal, ya que el presidente y vicepresidente del Senado solo pueden ser sustituidos en caso de muerte, ausencia o impedimento, y en ese momento Acevedo y Petta, presidente y vicepresidente primero del Senado respectivamente, estaban presentes en la cámara. La cámara tampoco estaba en sesión cuando la modificación del reglamento interno se llevó a cabo, agregando esta circunstancia a la ilegalidad del hecho. Finalmente, las modificaciones al reglamento interno ni siquiera se llevaron a cabo en la cámara sino que los legisladores votaron en la oficina de la bancada del Frente Guasu a escondidas. Este proceso fue apoyado por 25 senadores de la ANR, del PLRA, del Frente Guasu y de la UNACE. La modificación de los estatutos eliminó la capacidad del presidente del Senado de retener proyectos y bajó el umbral necesario para aprobar proyectos sin esperar los dictámenes de las comisiones (Abc Color 2017g).

Habiéndose abierto camino, el 31 de marzo, los mismos 25 senadores sesionaron de vuelta en la oficina de la bancada del Frente Guasu y aprobaron la enmienda para permitir la reelección presidencial (Abc Color 2017k). El proyecto de enmienda aprobado por esta sesión irregular del Senado modificaba cuatro artículos de la Constitución. El proyecto hubiese permitido: 1) la reelección del presidente por un periodo más, 2) la reelección de los gobernadores por un periodo más, 3) que el presidente pase inmediatamente a integrar las listas del Senado en el caso de perder las elecciones, y 4) que los parientes directos del presidente puedan candidatearse para la presidencia (Abc Color 2017j).

En reacción a la enmienda aprobada en esta sesión irregular, hubo una inmensa manifestación de ciudadanos paraguayos acompañados por políticos de la oposición frente al congreso la misma noche del 31 de marzo. Las movilizaciones, que empezaron siendo pacíficas, rápidamente se salieron de control y los manifestantes y las fuerzas policiales tuvieron encuentros violentos. La policía disparó con balas de goma a los manifestantes y también utilizaron gas lacrimógeno. El diputado liberal Edgar Acosta recibió un disparo de bala de goma en el rostro después de un encuentro con la policía antimotines y tuvo que ser hospitalizado (Última Hora 2017b). La policía nacional también ingresó violentamente a las oficinas del directorio del Partido Liberal y disparó y mató 
a Rodrigo Quintana —un funcionario del partido (Abc Color 2017n; González Bozzolasco 2017). Todavía no queda claro bajo órdenes de quién la policía entró al Partido Liberal ni cuál era el propósito de la redada, pero claramente fue un abuso de fuerza por parte de la institución. Después del -o tal vez a causa del- uso desmedido de fuerza, la policía fue retirada de enfrente del Congreso Nacional. Una porción de los manifestantes, viendo que la policía ya no estaba presente, entró y quemó el edificio, destruyendo así las oficinas de los legisladores paraguayos (Abc Color 2017m).

En ese momento, se asumía que en la Cámara de Diputados habría una mayoría suficiente para pasar la enmienda, y la cámara baja tenía planeado reunirse el día siguiente (1 de abril) para tratar el proyecto. Después de las manifestaciones y los disturbios, el presidente de la Cámara de Diputados Hugo Velázquez (ANR) anunció que desconvocó la sesión extraordinaria del 1 de abril para dar paz a la ciudadanía (Abc Color 2017i). En reacción a la respuesta policial desmedida, el 1 de abril, el presidente Cartes también destituyó al ministro del Interior, Tadeo Rojas, y al Comandante de la Policía, Críspulo Sotelo, y nombró a Lorenzo Darío Lezcano Sánchez y Luis Carlos Rojas Ortiz como sus reemplazos, respectivamente (Última Hora 2017c). Así las manifestaciones pararon el avance de la enmienda en el proceso legislativo.

\section{Desenlace de la crisis}

Aunque las manifestaciones pararon el avance de la enmienda, el temor después del 1 de abril era que la Cámara de Diputados todavía pudiera sesionar en cualquier momento y aprobarla. Pero el nivel de destrucción causado y las presiones extranjeras, como los mensajes de México, Estados Unidos, Uruguay, la Organización de Estados Americanos, la Corte Interamericana de Derechos Humanos, entre otros, hicieron que el presidente Cartes desistiera de avanzar con la enmienda temporalmente (Abc Color 2017o; Abc Color 2017l; Abc Color 2017p; Última Hora 2017e; Última Hora 2017d). Sin embargo el mensajero extranjero que pareció tener el mayor efecto sobre el presidente Cartes fue la Iglesia Católica.

El 2 de abril, Cartes propuso abrir una mesa de diálogo para reestablecer comunicación con los opositores de la enmienda e invitó a la Conferencia Episcopal Paraguaya (CEP) a participar de este espacio² (González Bozzolasco 2017). La primera mesa de diálogo fue el 5 de abril e incluyó a algunos políticos de la oposición, pero en la segunda, el 7 de abril, ya nadie de la oposición se presentó. A pesar de esto, parecería que la CEP y la Iglesia Católica en general influyeron en la decisión de Cartes y finalmente lo persuadieron de abandonar la enmienda. El indicio más evidente de esto fue que el 17 de abril Cartes escribió

Antes de las manifestaciones la CEP había anunciado que estaba en contra de la enmienda para permitir la reelección (Abc Color 2017e; Abc Color 2017h). 
una carta abierta donde comunicaba que estaría desistiendo de presentarse como candidato a presidente de la República, y esta carta estaba dirigida al monseñor Edmundo Valenzuela, arzobispo de Asunción y presidente de la CEP, y no a la ciudadanía paraguaya ni a los miembros de la oposición (Abc Color 2017q). El 27 de abril la Cámara de Diputados finalmente trató, rechazó y archivó el proyecto, dando así un fin definitivo a la crisis de la enmienda (Abc Color 2017r).

\section{ANTELACIÓN A LAS INTERNAS PARTIDARIAS}

Una vez concluida la crisis, las mismas facciones políticas que compitieron a favor y en contra de la enmienda fueron las que compitieron en las internas de sus respectivos partidos. Dentro del Partido Colorado el movimiento "Honor Colorado" tuvo que decidir quién sería el reemplazo de Horacio Cartes como precandidato a presidente. Por otra parte, los liberales tuvieron que reglamentar las alianzas que el PLRA llevaría a cabo con otros partidos de la oposición. En las siguientes subsecciones discutiré los procesos políticos que ocurrieron con antelación a las internas. Para hacerlo, analizaré 1) la reorganización de los movimientos internos de los partidos tradicionales y sus candidatos, 2) una intervención importante del TSJE en estas elecciones internas, 3) la ley de financiamiento político que el Congreso discutió antes de las internas, 4) movimientos sociales que ocurrieron con antelación a las internas no relacionados con la enmienda, y 5) los escándalos políticos que ocurrieron antes de las internas.

\section{Movimientos internos y formación de alianzas}

En el Partido Colorado, dado que Cartes fue impedido de ser precandidato a presidente, el ministro de Hacienda Santiago Peña se volvió el candidato del movimiento "Honor Colorado". El apoyo a la candidatura de Peña fue un intento de Cartes de elegir un sucesor directo. ${ }^{3}$ El 5 de junio Peña renunció para dedicarse a la campaña, y para reemplazarlo Lea Giménez asumió como ministra de Hacienda. Esta fue la primera vez que una mujer ocupó esta posición en el Paraguay (Última Hora 2017f). La competencia principal de Peña fue el mismo Mario Abdo, del movimiento "Añetete", que lideró la oposición a la enmienda dentro del Partido Colorado. Inhabilitado de candidatearse como presidente, Horacio Cartes pasó a ser el número uno en la lista de senadores del movimiento "Honor Colorado", y el vicepresidente de la República, Juan Afara, entró a la lista de senadores de "Añetete". 
La decisión para el electorado colorado, en términos del Ejecutivo, era una entre outsiders y colorados de vieja guardia. Horacio Cartes fue un outsider en su momento, ya que nunca había votado antes de hacerlo por sí mismo y “apenas se inscribió en el Registro Permanente en 2009" (Duarte Recalde 2013). Originalmente, Cartes no estaba habilitado para ser candidato a presidente para la ANR, y el estatuto del Partido Colorado tuvo que ser modificado para que pudiera candidatearse (Abente Brun 2012). De forma parecida, Santiago Peña también era un outsider ya que anteriormente estaba afiliado al Partido Liberal, y recién se afilió al Colorado cuando el partido presionó para que todos los ministerios estuvieran en manos de oficiales colorados (Última Hora 2016).

En contraste, Mario Abdo Benítez tiene una larga trayectoria colorada. El padre de Mario Abdo (llamado de la misma manera) fue secretario privado de Alfredo Stroessner. Abente Brun (2008) describió a Mario Abdo (hijo) como parte del "stronismo de tercera generación". Durante su campaña, Mario Abdo intentó distanciarse del stronismo, y quedará por verse hasta qué punto realmente se identifica con los valores de la dictadura pasada. Pero es seguro decir que la trayectoria partidaria y tradicionalista de Mario Abdo Benítez es cualitativamente diferente del perfil outsider, tecnocrático y neoliberal de Santiago Peña.

En el Partido Liberal, los principales candidatos eran Efraín Alegre — presidente del partido y candidato por el "Movimiento 2018" - y Carlos Mateo Balmelli —senador del periodo 2004-2008 y candidato por el movimiento "Equipo Joven" - En el "Equipo Joven" también se encontraba Blas Llano, el mayor propulsor de la enmienda dentro del Partido Liberal, en el segundo puesto de la lista de senadores del movimiento. Este partido no eligió un candidato a vicepresidente porque en su convención se decidió que intentaría implementar una alianza con otros partidos, y el puesto de vicepresidente quedaría para uno de los aliados (La Nación 2017). Tras las internas, esta posición fue ocupada por un miembro del Frente Guasu.

Según las leyes paraguayas, hay dos mecanismos que los partidos políticos pueden usar para presentarse a unas elecciones de manera conjunta: la alianza y la concertación (Código Electoral 1996; Martínez 2007). Los convencionalistas liberales decidieron avanzar con la alianza. Esta decisión es relevante porque no requiere que las organizaciones estén aliadas en todas las carreras. Aunque los partidos y movimientos aliados presentaron un solo candidato a presidente bajo la "Alianza Ganar", varios partidos y movimientos presentaron listas a senadores y diputados independientemente a la alianza. Notablemente, el Frente Guasu tuvo su propia lista de senadores independiente de la lista del PLRA, a pesar de que la dupla presidencialista de la "Alianza Ganar" consistía en un liberal como presidenciable y uno del Frente Guasu como candidato a vicepresidente.

Esta estrategia podría resultar problemática para la oposición porque el mecanismo D'hondt favorece a los partidos más grandes; entonces una fragmentación de listas entre los partidos de izquierda, el Partido Liberal 
y otros partidos de la oposición podría llevar a una mayor cantidad de votos desperdiciados para la oposición frente a un Partido Colorado unido - especialmente en la Cámara de Diputados, ya que distritos más pequeños suelen ser menos proporcionales (Gallagher y Mitchell 2005). Entonces, las alianzas parecen ser necesarias para tener una oportunidad de llevar a un candidato no colorado a la presidencia, como demostró la elección de Lugo en su momento (Brugnoni 2009). Pero de seguir bajo la estrategia de presentar alianzas presidenciales sin acuerdos legislativos o listas conjuntas en un sistema D'hondt, la oposición siempre será menos eficiente que la ANR en traducir votos a escaños. Sin acuerdos legislativos, presidentes opositores también serían más vulnerables a la fragmentación de su coalición, dificultando potencialmente la gobernabilidad y, en el peor de los casos, aumentando las chances de juicio político para un presidente opositor.

\section{Intervención del Tribunal Superior de Justicia Electoral}

El lector atento se habrá dado cuenta de que la convención liberal aprobó sanciones para los legisladores que apoyaban la enmienda, pero Blas Llano apoyó la enmienda y de todas maneras consiguió estar en la lista de senadores del movimiento "Equipo Joven" dentro del PLRA. En realidad la ANR y el PLRA aprobaron sanciones para sus legisladores que no apoyaban o apoyaban la reelección, respectivamente. La razón por la cual las sanciones no fueron implementadas fue porque el Tribunal Superior de Justicia Electoral (TSJE) las invalidó. El TSJE justificó esta acción utilizando el Artículo 201 de la Constitución, el cual establece que "los senadores y diputados no estarán sujetos a mandatos imperativos" (Constitución Nacional 1992). Esta interpretación de la Constitución no es nueva, y legisladores ya la han usado para justificarse cuando han votado en contra de su partido en el pasado. El efecto de este artículo, y su interpretación por las cortes, es que limita la capacidad de los partidos de mantener la disciplina interna ya que dificulta sancionar a aquellos legisladores que se alejan de las posturas emanadas de estos.

\section{Leyes electorales consideradas por el Congreso}

La ley de financiamiento político fue el proyecto de ley más discutido previo a las internas partidarias. Esta ley buscaba expandir la capacidad del TSJE de regular las fuentes de financiamiento de los movimientos intrapartidarios durante las internas. El proyecto fue dilatado varias veces por la Cámara de Diputados y finalmente ningún tipo de restricción a las campañas de las internas partidarias fue aprobada (Última Hora 2017g). La ley de financiamiento político actual está limitada a controlar las elecciones generales y no las internas partidarias (Última Hora 2017j). Consecuentemente, las internas se llevaron a cabo con muy pocas regulaciones sobre su financiamiento, y durante sus campañas, por ejemplo, 
ambos precandidatos a presidente del Partido Colorado dijeron no saber cuánto gastaron (Última Hora 2017k; Última Hora 2017l).

\section{MOVIMIENTOS SOCIALES}

Además de las manifestaciones que se llevaron a cabo para intentar impedir la enmienda, hubo por lo menos dos instancias adicionales donde la ciudadanía se manifestó en las calles. La primera movilización social tuvo que ver con campesinos presionando al congreso para conseguir que sus deudas sean subsidiadas por el Estado. En respuesta a estas manifestaciones, la izquierda — compuesta por el Frente Guasu, Avanza País y Partido Encuentro Nacionaljunto con partes del PLRA y del Partido Colorado, aprobó una ley que declaraba emergencia nacional y contemplaba crear nuevas instituciones que estarían encargadas de proveer asistencia técnica y crediticia, acceso a servicios básicos, vivienda y tierra para las familias campesinas. También se aprobó otra ley que subsidiaría las deudas vencidas de los campesinos, siempre que los deudores fueran dueños de fincas que no superaran las 30 hectáreas (Última Hora 2017h). Estos proyectos fueron fuertemente criticados por la ministra de Hacienda Lea Giménez, que argumentaba que eran proyectos de ley fiscalmente irresponsables, y eventualmente fueron vetados por el Ejecutivo (Última Hora 2017i). A pesar de que las políticas no fueron adoptadas, esta fue una situación donde el campesinado influyó directamente en la agenda política con sus manifestaciones.

La segunda instancia fue el movimiento titulado "Ni una menos" en las redes sociales. En esta ocasión cientos de personas se manifestaron frente a la Catedral Metropolitana para protestar contra la violencia contra la mujer (Abc Color 2017t). A pesar de que ninguna política pública resultó directamente de esta manifestación, sí fue el inicio de una serie de manifestaciones sobre temas de género que se llevaron a cabo durante 2017 e inicios de 2018. En marzo de 2018 el Senado aprobó un proyecto de ley de paridad, en parte gracias a una marcha que se organizó en coincidencia con el día de la mujer (Última Hora 2018). A la hora de escribir este ensayo el proyecto no se aprobó ni se rechazó, pero el hecho de que esté en la agenda política se debe en parte a la serie de manifestaciones de género que empezaron en 2017.

\section{Escándalo político}

Hubo un escándalo político que seguramente afectará las elecciones generales de 2018, y tuvo que ver con el senador y presidente del Jurado de Enjuiciamiento de Magistrados (JEM) Óscar González Daher (ANR). En noviembre de 2017, se filtraron unos audios entre un secretario del JEM, Raúl Fernández Lippmann, y una fiscala, Karina Giménez. En ellos Lippmann y Giménez estaban discutiendo un intercambio de favores donde el JEM permitiría a la fiscala mantener su 
cargo y ella bloquearía una causa de usurpación donde uno de los implicados era el hermano del senador González Daher (Última Hora 2017m).

Estos audios causaron muchas controversias y políticos no aliados a González Daher empezaron a pedir su remoción del cargo. González Daher, además de senador y presidente del JEM, figuraba también en el tercer lugar de la lista de senadores del movimiento "Honor Colorado" de Horacio Cartes. El 22 de diciembre de 2017, 30 senadores votaron para destituir a González Daher. Esta fue la primera vez en el periodo democrático que el artículo 201 de la Constitución se aplicó, donde un legislador pierde su investidura por "el uso indebido de influencias" (Última Hora 2017n). Similarmente, en otros audios se encontró que el senador del partido UNACE Oviedo Matto solicitaba dinero a una fiscala, pero a diferencia de González Daher los senadores aceptaron la renuncia de Matto y no procesaron su pérdida de investidura (Última Hora 2017o).

\section{INTERNAS PARTIDARIAS}

Se podría suponer que la llegada de las internas resolvería las competencias por poder que las facciones de los partidos tradicionales mantuvieron desde el inicio del año. Aunque esto es cierto en relación con las posiciones ejecutivas, el hecho de que las listas de cada partido se determinan utilizando el mecanismo de representación proporcional $\mathrm{D}^{\prime}$ hondt significa que era muy difícil que las facciones internas no recibieran algo de representación en la chapa final de cada partido (Turner 2010). Como veremos en esta sección, aunque los resultados de las internas aclararon qué facción controlaría la nominación a presidente de cada partido, los resultados internos a posiciones de gobernadores, senadores y diputados no darían una victoria clara a ninguno de los movimientos. Esto significa que la dinámica de competencia interna dentro de cada partido se mantendría en el tiempo, ya que las facciones que compitieron en el pasado seguirían existiendo en el futuro.

\section{Resultados internas: presidente}

El 18 de diciembre de 2017 las elecciones internas se llevaron a cabo sin conmoción y de manera organizada. Al finalizar el día electoral los resultados fueron aceptados por todos los precandidatos. Como ya fue mencionado, los principales precandidatos a presidente dentro del Partido Colorado eran Santiago Peña por el movimiento "Honor Colorado", y Mario Abdo Benítez por el movimiento "Añetete". En el Partido Liberal los principales precandidatos eran Efraín Alegre por el "Movimiento 2018" y Carlos Mateo Balmelli por el movimiento "Equipo Joven". En las internas del Partido Colorado participaron 1.050.878 personas y las del Partido Liberal 454.141 personas. Finalmente, en el Partido Colorado, Mario Abdo resultó ganador con el 54\% de los votos del 
electorado y, en el Partido Liberal, Efraín Alegre triunfó con el 68\% de los votos liberales (TSJE 2017). Los resultados de presidenciables colorados muestran una clara victoria para la vieja guardia colorada en contra del movimiento más outsider y neoliberal. En los resultados liberales vemos un fuerte rechazo al candidato del movimiento "Equipo Joven" — la facción liberal que apoyó la enmienda constitucional.

Figura 1: Composición de listas del Senado: Partido Colorado

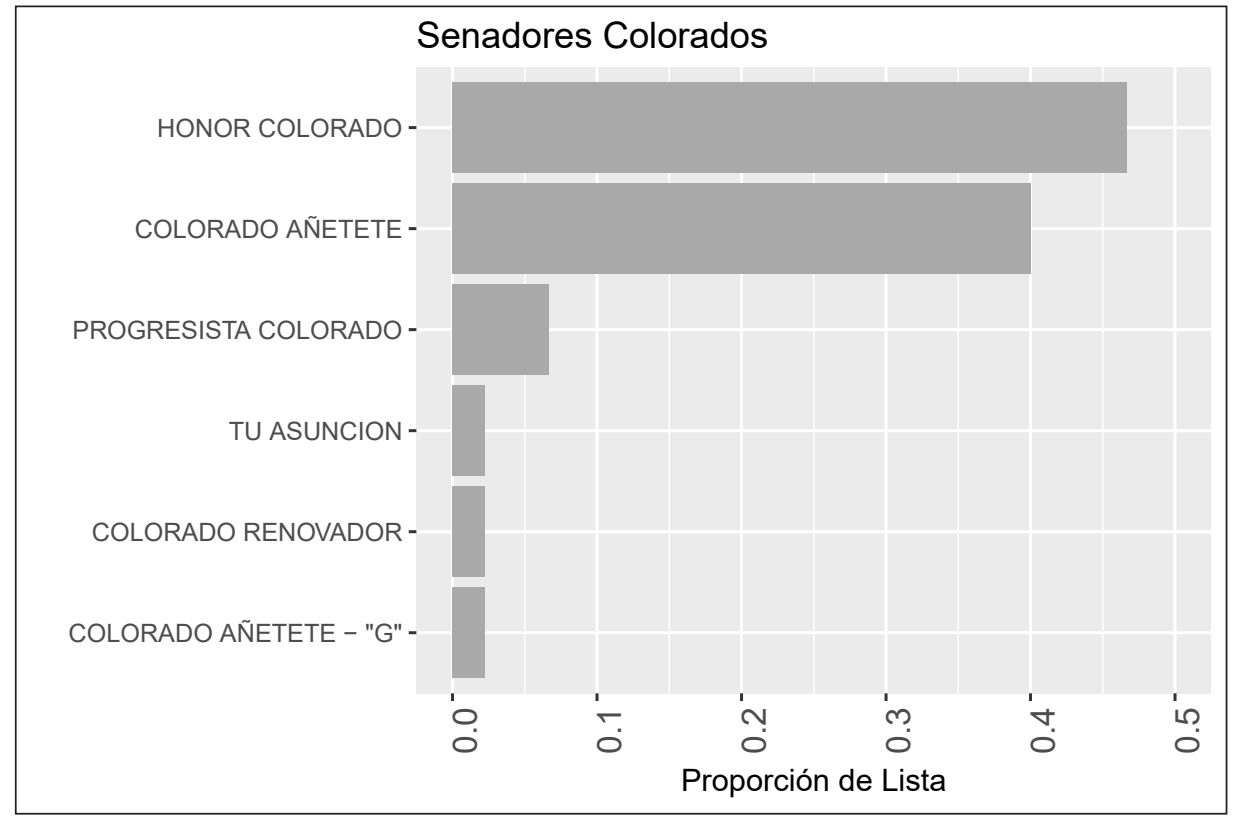

Fuente: elaboración propia con datos del TEP (2018)

\section{Resultados internas: senadores}

A pesar de que ambos partidos tuvieron internas presidenciales con sólo dos candidatos principales, el Partido Colorado tuvo una menor cantidad de movimientos internos que el Partido Liberal. Esto se puede ver mirando la lista final de senadores para cada uno de los partidos. En la Figura 1 se ve claramente que en el Partido Colorado los movimientos "Honor Colorado" y "Colorado Añetete" son dominantes. Es interesante ver también que en el Partido Colorado, a pesar de que "Añetete" ganó la presidencia con Mario Abdo, el movimiento "Honor Colorado" recibió más votos en la lista del Senado. El número uno en la lista de senadores de "Honor Colorado" fue Horacio Cartes.

En contrapartida, en el Partido Liberal ninguno de los movimientos son dominantes, como puede notarse en la Figura 2. Ocho movimientos internos liberales alcanzaron su lista del Senado y ninguno alcanzó ni superó el 30\% de 
los lugares en la lista final. El movimiento que más representación recibió en la lista partidaria fue el movimiento "Equipo Joven", pero de ninguna manera fue un movimiento dominante.

Figura 2. Composición de Listas del Senado: Partido Liberal

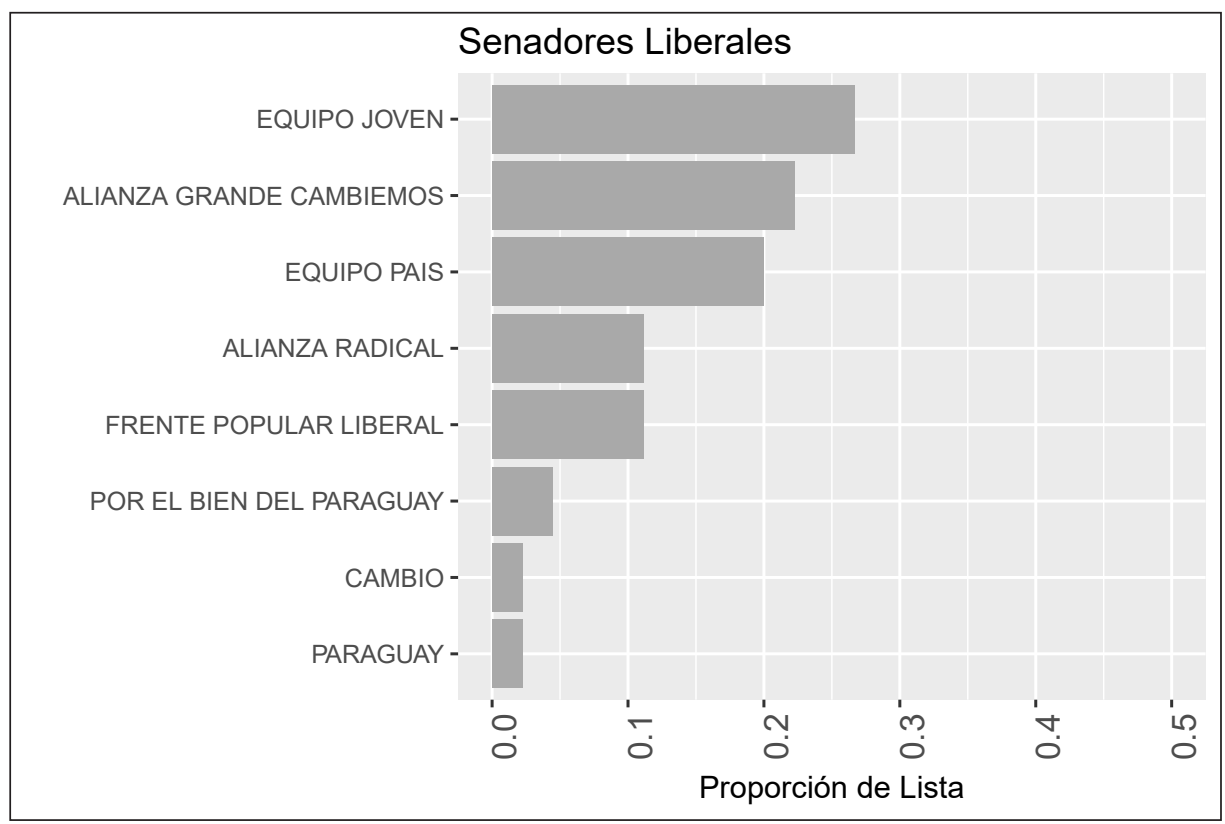

Fuente: Elaboración propia con datos del TEI (2017) y TSJE (2018)

\section{Resultados Internas: Gobernaciones}

La mayor fragmentación de los liberales en relación con los colorados también puede verse en los resultados internos de candidatos a la gobernación representados en la Figura 3. Dentro del Partido Colorado al movimiento "Honor Colorado" le fue mejor que a "Añetete", ya que el primero ganó 11 gobernaciones mientras que el segundo solo obtuvo 5. En contrapartida, en el Partido Liberal no se puede ver ningún movimiento realmente dominante en términos de candidatos a gobernación. Adicionalmente, las internas liberales a gobernadores también tienen la particularidad de que decidieron no presentar candidatos para algunos departamentos ya que ingresarán a esas carreras como miembros de la "Alianza Ganar". De las carreras a gobernación, entonces, 5 asientos no contarían con un candidato liberal y en sus lugares se estarían presentando candidatos de otros partidos de la alianza. 
Figura 3. Candidatos colorados y liberales para la gobernación

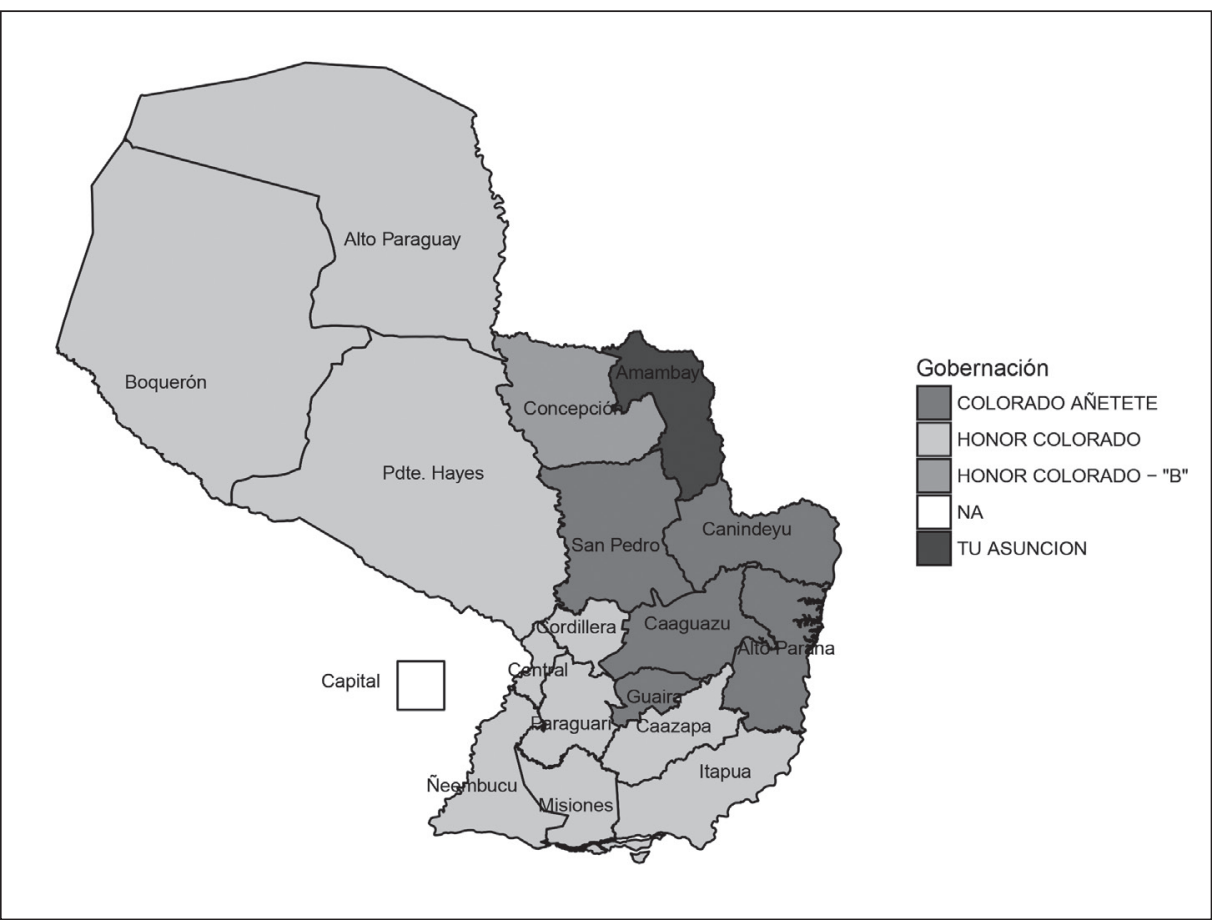

Fuente: elaboración propia con datos del TEP (2018)

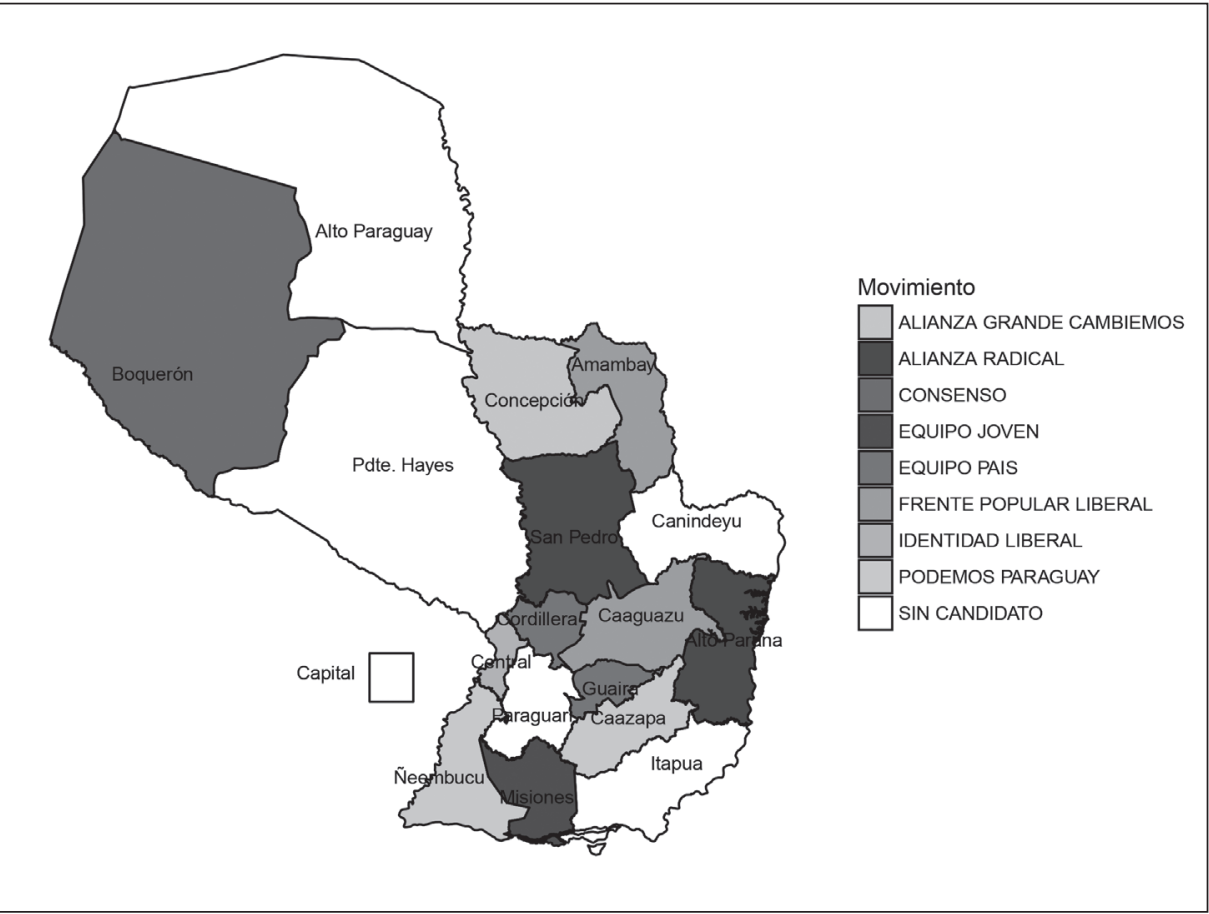

Fuente: elaboración propia con datos del TEI (2017) y del TSJE (2018) 
Figura 4: Presencia en listas de diputados

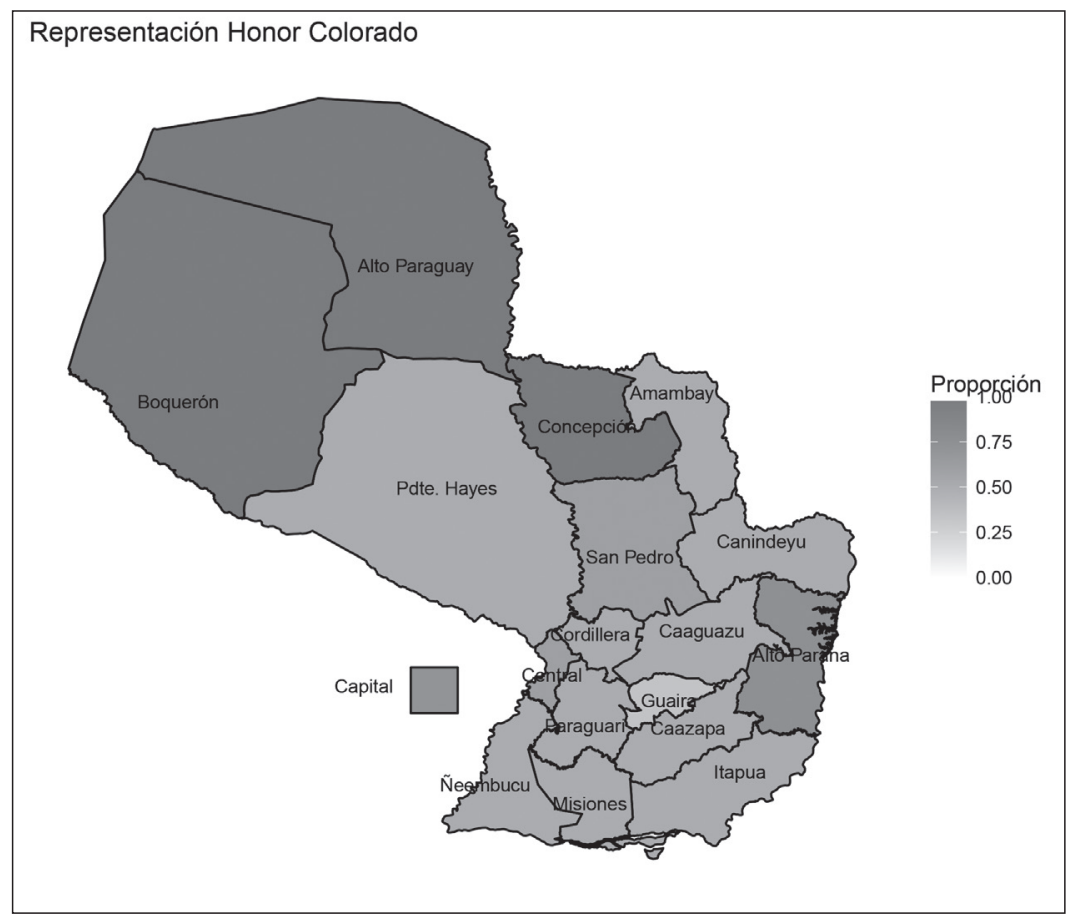

Fuente: elaboración propia con datos del TEP (2018)

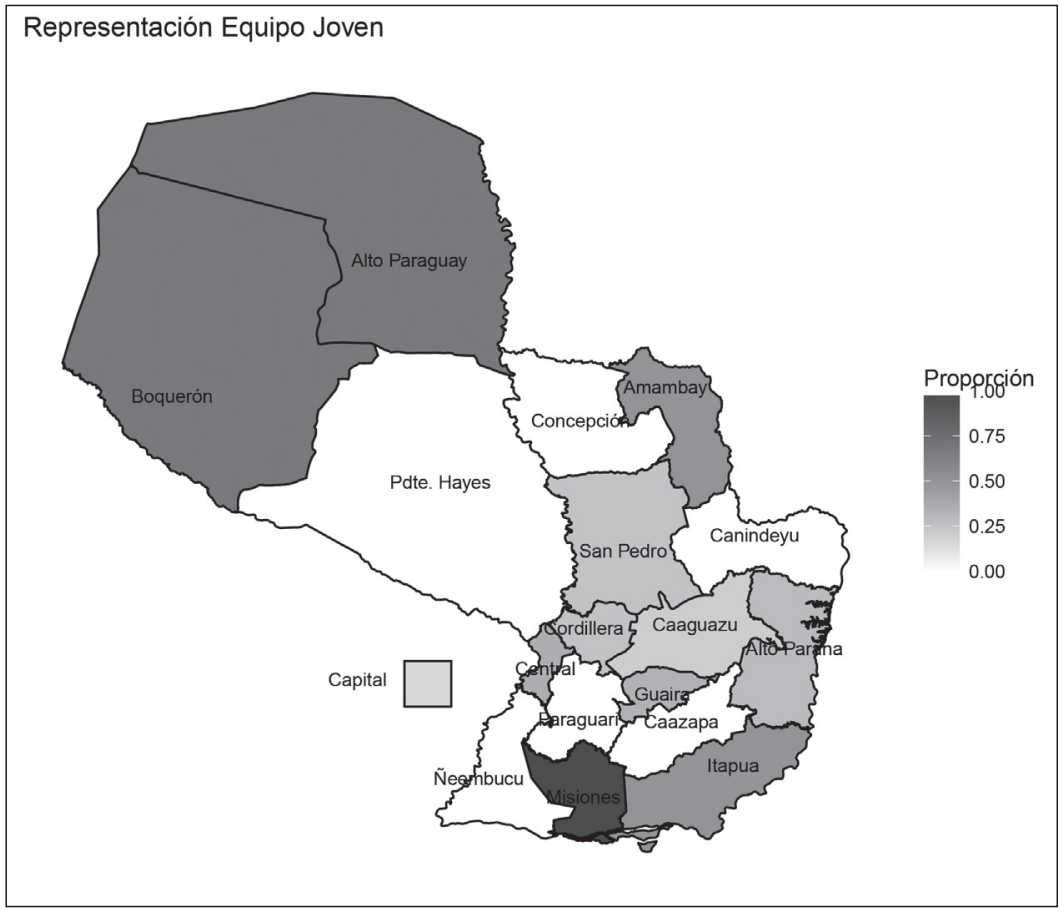

Fuente: elaboración propia con datos del TEI (2017) y del TSJE (2018) 


\section{Resultados internas: diputados}

Teniendo en cuenta que el movimiento "Honor Colorado" es antagónico a Abdo, y "Equipo Joven" es antagónico a Alegre, decidí visualizar los resultados de las internas a diputados resaltando el nivel de oposición que cada candidato presidencial recibiría por parte de su propio partido. En la Figura 4 se puede ver la proporción de cada lista departamental que recibió cada movimiento. Cuanto más oscuro el color, mayor competencia interna recibiría cada candidato por parte de su propio partido dentro de cada departamento. ${ }^{4}$

El gráfico del Partido Colorado muestra que Abdo tendría más control de sus legisladores en Guairá, Caaguazú, Paraguarí, San Pedro y Amambay, pero que en general la presencia de "Honor Colorado" sería muy alta en todos los departamentos. En contraste, la oposición que Alegre vería por parte de su propio partido parecería ser bastante baja ya que el "Equipo Joven" no es una fuerza extremadamente dominante. Lo que sí queda claro es que sin importar qué partido gane las elecciones generales, los partidos tradicionales no se librarían de las facciones internas que compitieron tanto durante el 2017. Es muy probable que estas tensiones sigan existiendo dentro de ambos partidos. La fuerza de "Honor Colorado" dentro de la ANR es particularmente notable.

\section{ECONOMÍA}

En esta sección me enfocaré en cuatro factores económicos: el crecimiento del PIB, la recaudación del Estado, la deuda externa y los niveles de pobreza del Paraguay. Los datos económicos expuestos a continuación muestran que a pesar del crecimiento estable del país, la dependencia del Estado sobre impuestos regresivos como la principal fuente de ingresos limita el crecimiento de la recaudación. También, se nota un aumento en la deuda externa como consecuencia de la emisión de bonos soberanos y, finalmente, se puede notar que a pesar de que el Paraguay crece económicamente de una manera sostenida, este crecimiento económico no se traduce a una reducción de los niveles de pobreza del país.

$4 \quad$ El Partido Liberal no presenta candidatos en Boquerón y Alto Paraguay, departamentos que solo tienen un escaño. 
Figura 5. Indicadores económicos

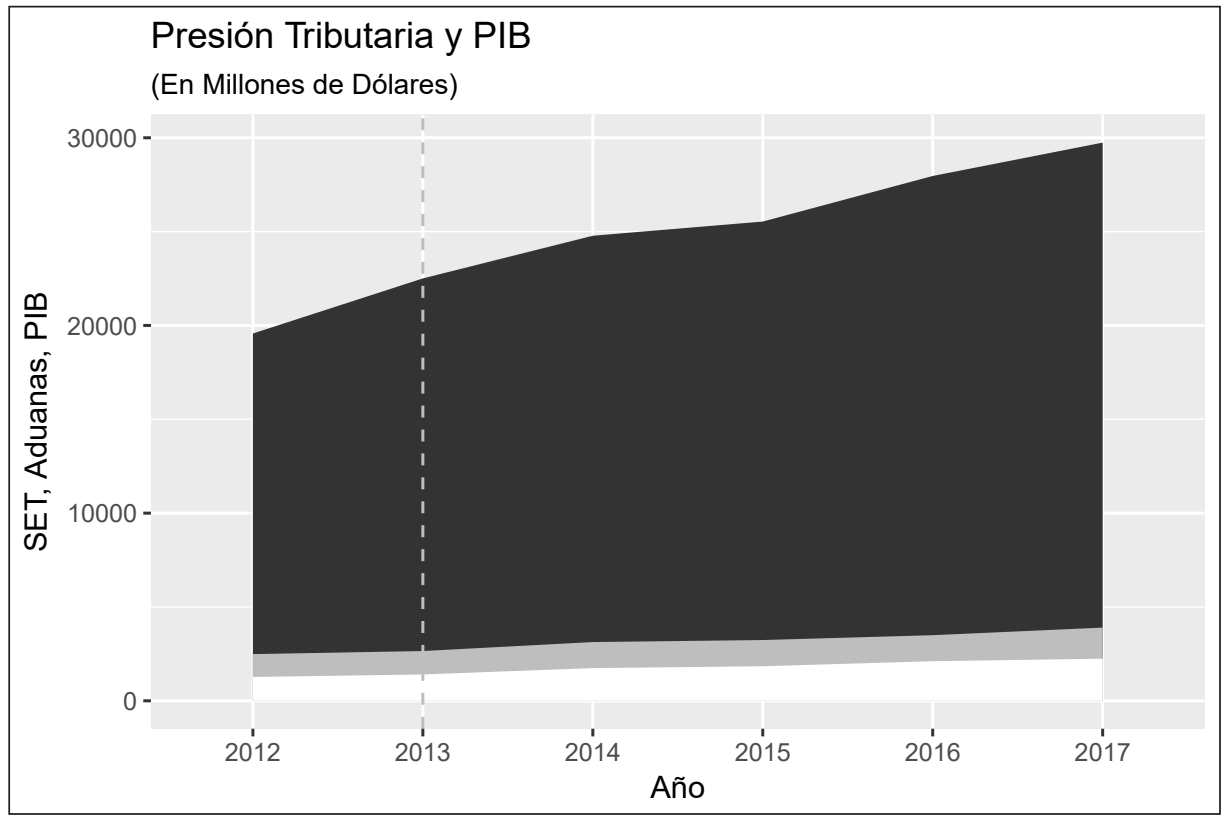

Fuente: Elaboración propia con datos de la SET (2017) / \$1=Gs. 5.561

La Figura 5 muestra el nivel de recaudación del Estado, por parte de la Subsecretaría de Estado de Tributación (SET) y Aduanas en relación con el PIB nacional (SET 2017). El gráfico muestra que el Paraguay ha tenido un crecimiento económico estable desde el $2012 .{ }^{5}$ Igualmente, el nivel de recaudación ha crecido a través de los años, pero el de crecimiento de la recaudación es bastante inferior al crecimiento del PIB. Habiendo dicho esto, podría afirmarse que durante la presidencia de Horacio Cartes el país mantuvo un buen nivel de crecimiento económico durante todo el periodo, aun cuando el nivel de recaudación del Estado no ha crecido considerablemente en relación con este crecimiento.

La Figura 6 se enfoca solamente en las recaudaciones del Estado y muestra el detalle sobre sus fuentes de ingreso. La porción blanca del gráfico representa lo percibido por el Impuesto al Valor Agregado (IVA). La pequeña raya negra encima del IVA representa los ingresos que el Estado recaudó a través del Impuesto a la Renta Personal (IRP). La porción gris clara representa los demás ingresos de la SET, que se componen de la la suma del Impuesto a la Renta Agropecuaria (IMAGRO) y el Impuesto a la Renta Comercial, Industrial y de Servicios (IRACIS). Finalmente, la porción gris oscura del gráfico representa los ingresos del estado a través de Aduanas. 
Figura 6. Indicadores económicos (Cont.)

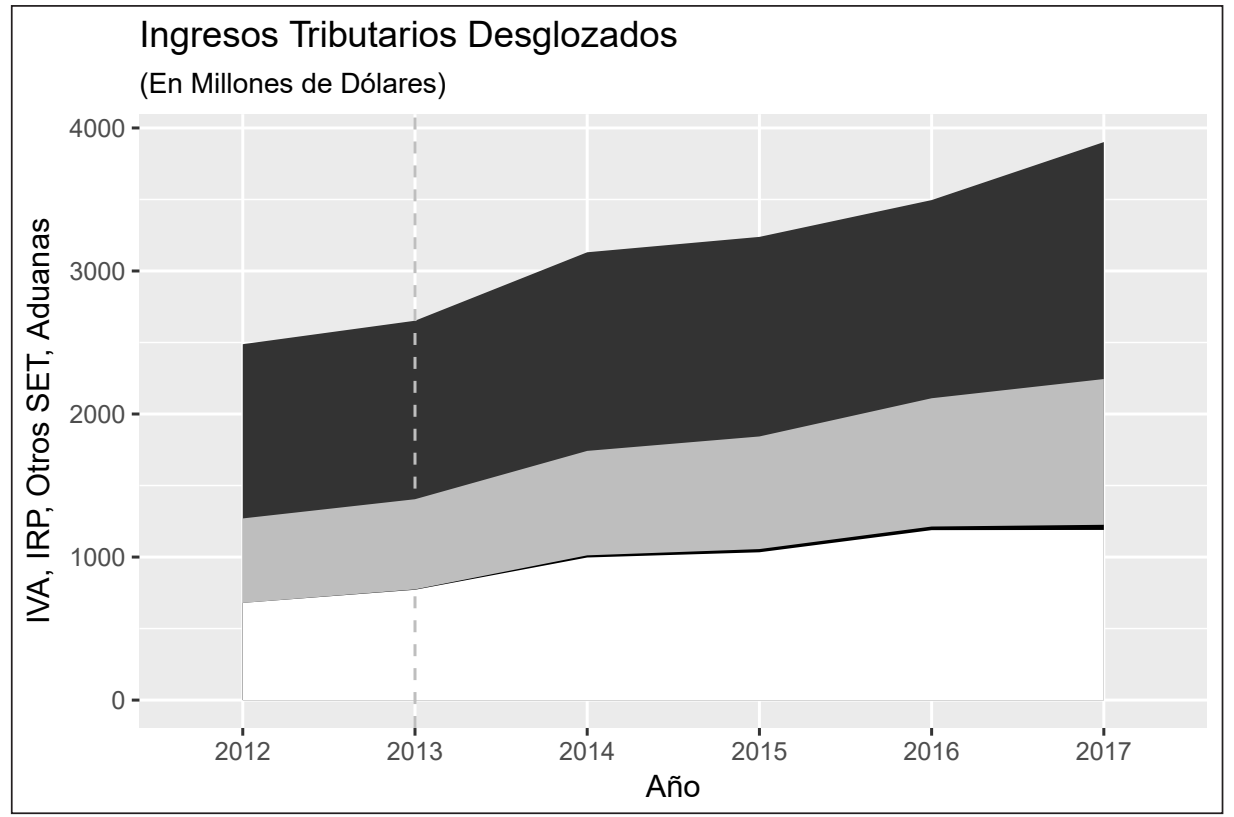

Fuente: Elaboración propia con datos de la SET (2017) / \$1=Gs. 5.561

En general, el gráfico muestra que sí hubo un crecimiento de recaudación por parte del Estado. Sin embargo, si nos enfocamos en las recaudaciones que ingresaron por la SET (los tres bloques inferiores), vemos que la mayor fuente de ingresos ha sido a través del IVA. Las recaudaciones a través del IRP están creciendo pero muy moderadamente. Finalmente, los ingresos por el IMAGRO e IRACIS parecerían haber mejorado, especialmente en 2017. Habiendo dicho eso, sin contar Aduanas, persiste el dato de que la mayor fuente de ingresos del Estado sigue siendo a través de los impuestos regresivos como el IVA. Aunque esperaríamos que hubiera una diversificación de ingresos en el futuro, especialmente en la medida en que el IRP sea expandido para alcanzar a porciones más amplias de la población, los mayores contribuyentes siguen siendo las clases más bajas del Paraguay. 
Figura 7. Indicadores económicos (Cont.)

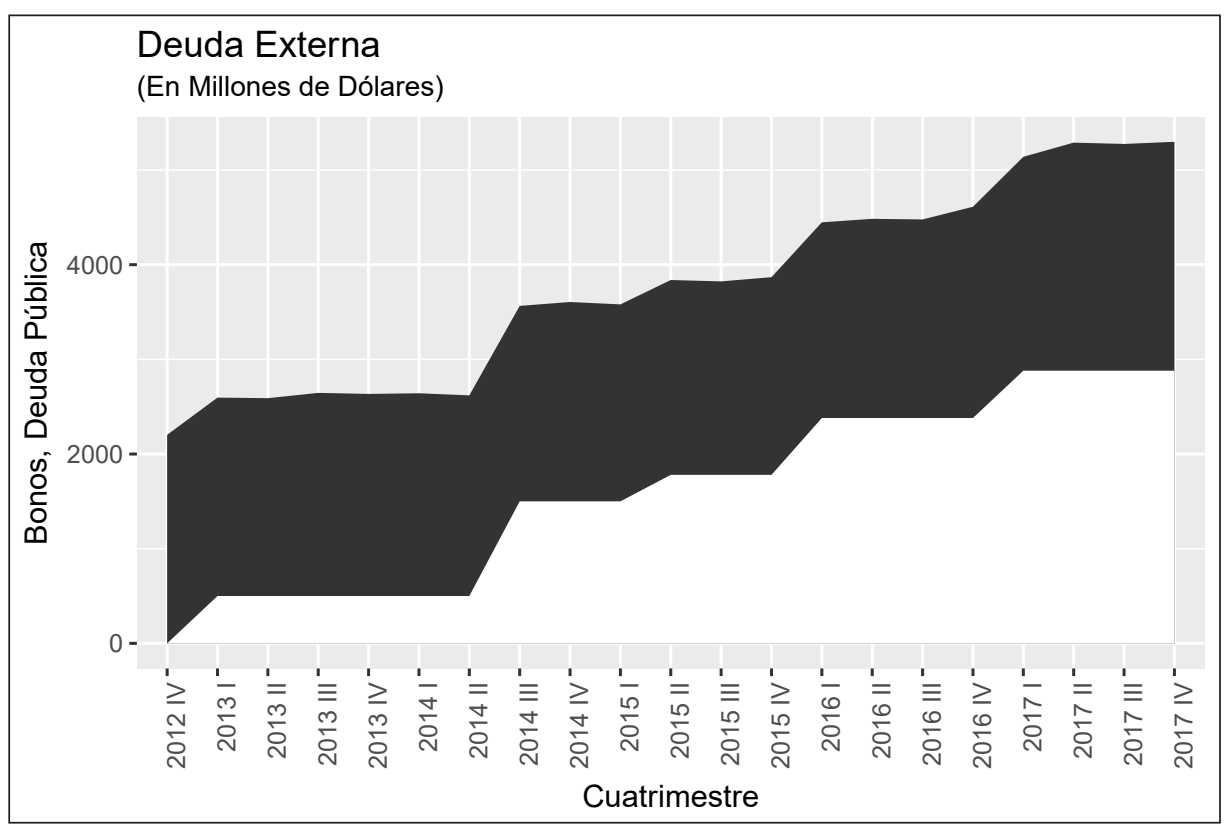

Fuente: elaboración propia con datos del BCP (2017) / \$1=Gs. 5.561

La Figura 7 muestra la deuda externa del Paraguay. El gris oscuro representa la deuda total del Estado, y el blanco la porción que se puede atribuir a la emisión de bonos soberanos. Este gráfico evidencia que el crecimiento de la deuda externa del país durante la presidencia de Cartes se llevó a cabo casi exclusivamente a través de estos bonos. Dentro del año 2017 hubo unas pequeñas fluctuaciones de la deuda externa que no serían atribuibles a la emisión de bonos soberanos, pero queda claro que durante la administración de Cartes predominó — de una manera superior a otros presidentes - el mecanismo de bonos soberanos para acceder a los recursos. 
Figura 8. Indicadores económicos (Cont.)

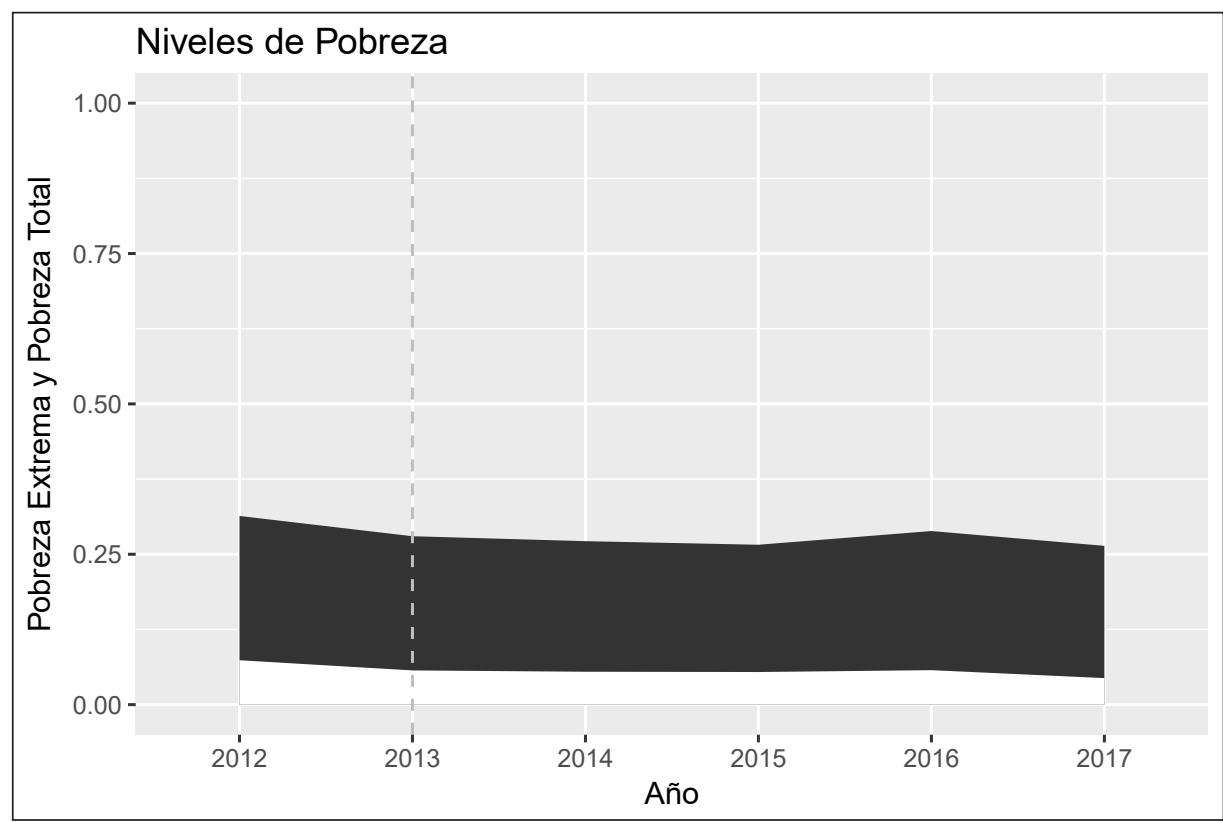

Fuente: elaboración propia con datos de la DGEEC (2017) / \$1=Gs. 5.561

Finalmente, la Figura 8 muestra los niveles de pobreza en el Paraguay desde 2012 hasta el presente. La porción blanca del gráfico representa la pobreza extrema y la porción gris la pobreza total. En general este gráfico evidencia que no hubo una reducción de pobreza significativa durante la presidencia de Cartes. Aunque tal vez haya habido una pequeña reducción de pobreza extrema, estos números dejan mucho que desear.

En resumen, los datos pintan un país que tiene crecimiento económico pero que aún no logra utilizarlo para mejorar la situación de sus ciudadanos más vulnerables. El nivel de pobreza se ha mantenido estable, a pesar del crecimiento, y la recaudación del Estado tampoco ha crecido al ritmo necesario para poder atender estos requerimientos. Es más, el hecho de que el Estado dependa tanto de fuentes de ingresos regresivos, como el IVA, ha de exacerbar y expandir la brecha entre los paraguayos. Finalmente, la dificultad de recaudación del Estado parece haber empujado al gobierno a ampliar su nivel de endeudamiento. Los bonos soberanos del país fueron la fuente principal de recursos durante el periodo de la presidencia de Cartes, y aunque probablemente no sea un problema todavía el crecimiento de la deuda sin ampliar las bases de recaudación podría convertirse en uno. 


\section{VII.EPÍLOGO}

Hay por lo menos dos problemas iniciados en el 2017 que no quedaron resueltos. El primer problema es que Horacio Cartes quedó como número uno de la lista de senadores del Partido Colorado. Según la Constitución nacional:

“Los ex presidentes de la República... serán senadores vitalicios de la Nación, salvo que hubiesen sido sometidos a juicio político y hallados culpables. No integrarán el quórum. Tendrán voz pero no voto" (Constitución Nacional 1992, Art. 189).

Lo más probable es que vuelva a haber una crisis constitucional porque, como número uno de la lista de senadores del Partido Colorado, es casi una certeza que Cartes salga electo aunque la Constitución no permite que sea senador.

Esta misma crisis ocurrió una vez en el pasado con el entonces presidente Nicanor Duarte Frutos (Abente Brun 2008). En ese momento, la Corte Suprema, influenciada por Duarte, aceptó la constitucionalidad de que esta fuera un senador regular (no vitalicio), pero el pleno del Senado no permitió que asumiera el escaño, y le dieron la posición a su suplente Jorge Céspedes, ANR (Abc Color 2017s). En 2018 tendremos que ver si ocurre lo mismo o si a Horacio Cartes se le permite asumir. Para sumar a las dificultades, Nicanor Duarte Frutos también está en la lista colorada para el Senado, entonces además tendremos que ver si los senadores lo dejan asumir o si lo inhabilitan.

Finalmente, el último problema que el 2017 despertó es la candidatura de Óscar González Daher. Como está número 5 en la lista de senadores, también es muy probable que reciba un escaño a pesar de no ser muy popular. En 2018, los legisladores tendrán que decidir si permitirán a González Daher asumir su escaño o si votarán para expulsarlo nuevamente una vez concluidas las elecciones.

2017 fue un año lleno de conflictos para el Paraguay. La primera mitad del año vivió conflictos no institucionalizados, donde facciones políticas utilizaron sus poderes de facto para distorsionar las reglas de juego a su favor. Estas distorsiones llevaron a reacciones extrainstitucionales por parte de los políticos opositores y la ciudadanía movilizada. La segunda mitad del año experimentó competencias políticas mucho más institucionalizadas y ordenadas. El TSJE trabajó para que las internas se llevasen a cabo de una manera transparente, las elecciones partidarias se realizaron sin violencia y sin distorsiones graves, y todos los participantes aceptaron la legitimidad de los resultados electorales - teniendo en cuenta que se hicieron sin regulaciones sobre el financiamiento político-. Si hay algo que 2017 muestra claramente es que los procesos institucionalizados tienen una mayor capacidad de resolver los conflictos entre las facciones políticas de una manera constructiva.

En este artículo vimos que los movimientos internos de cada partido siguieron recibiendo representación en las nominaciones finales de sus respectivos 
partidos. También analizamos que la interpretación del TSJE sobre los mandatos imperativos de los legisladores dificulta la implementación de la disciplina partidaria. Las facciones internas de los partidos tradicionales también cuentan con partidos no tradicionales (los partidos de izquierda), para crear coaliciones puntuales con miras a avanzar en ciertas políticas de interés mutuo. Dadas estas condiciones de coaliciones y fragmentación intrapartidarias, el conflicto político futuro parece ser inevitable, pero los daños causados por procesos informales y desinstitucionalizados no tienen por qué serlo.

\section{REFERENCIAS}

Abc Color. 2012, 23 de marzo. “¿Cómo se vota con la urna delivery?" Recuperado el 28 de mayo de 2018 de http://www.abc.com.py/especiales/fin-de-semana/como-se-votacon-la- urna-delivery-382528.html

Abc Color. 2013, 6 de mayo. "PLRA con nuevo presidente." Recuperado el 28 de mayo de 2018 de http:/ / www.abc.com.py/nacionales/plra-con-nuevo-presidente-569273.html.

Abc Color. 2016, 25 de agosto. "Sepultan reelección por vía enmienda durante un año." Recuperado el 28 de mayo de 2018 de http://www.abc.com.py/nacionales/bloqueanrekutu-via-enmienda-1512142.html

Abc Color. 2017a, 27 de febrero. "Violenta reacción de políticos para mantener sus privilegios." Recuperado el 28 de mayo de 2018 de http://www.abc.com.py/edicion-impresa/ politica/violenta-reaccion-de-politicos-para-mantener-sus-privilegios- 1568683.html

Abc Color. 2017b, 23 de marzo. "El 22 de agosto, fecha límite para violadores." Recuperado el 28 de mayo de 2018 de http://www.abc.com.py/nacionales/el-22-de-agosto-fechalimite- para-violadores-1576759.html

Abc Color. 2017c, 27 de marzo. “¿Primer paso para enmienda?" Recuperado el 28 de mayo de 2018 de http://www.abc.com.py/nacionales/primer-paso-para-enmienda-1578069. html

Abc Color. 2017d, 28 de marzo. "El cartismo comienza a ejecutar su plan de atropello a la Constitución Nacional." Recuperado el 28 de mayo de 2018 de http://www.abc. com.py/edicion-impresa/politica/el-cartismo-comienza-a-ejecutar-su- plan-de-atropello-a-la-constitucion-nacional-1578185.html

Abc Color. 2017e, 28 de marzo. "Freno a enmienda para evitar violencia." Recuperado el 28 de mayo de 2018 de http://www.abc.com.py/nacionales/freno-a-enmienda-para-evitar- violencia-1578604.html

Abc Color. 2017f, 28 de marzo. "Titular del Congreso rechaza pedido de sesión extra." Recuperado el 28 de mayo de 2018 de http:/ / www.abc.com.py/nacionales/rechazan- pedido-de-sesion-1578306.html

Abc Color. 2017g, 29 de marzo. "Atropellan el Senado y usurpan su presidencia." Recuperado el 28 de mayo de 2018 de http:/ / www.abc.com.py/edicion-impresa/politica/atropellan-el- senado-y-usurpan-su-presidencia-1578589.html

Abc Color. 2017h, 29 de marzo. "Iglesia pide rechazar enmienda para evitar violencia en el país." Recuperado el 28 de mayo de 2018 de http://www.abc.com.py/edicion- impresa/politica/iglesia-pide-rechazar-enmienda-para-evitar-violencia-en-el-pais1578621.html

Abc Color. 2017i, 31 de marzo. "Hugo Velázquez: 'Para dar paz suspendimos la sesión de mañana'." Recuperado el 28 de mayo de 2018 de http:/ / www.abc.com.py/730am/momento-justo/hugo-velazquez-para-dar-paz- suspendimos-la-sesion-de-manana-1579686.html

Abc Color. 2017j, 31 de marzo. "¿Qué quieren modificar los violadores?" Recuperado el 28 de mayo de 2018 de http:/ / www.abc.com.py/nacionales/que-modificaron-los-violadores- 1579576.html 
Abc Color. 2017k, 31 de marzo. "Sesión a 'escondidas' en el Senado." Recuperado el 28 de mayo de 2018 de http://www.abc.com.py/nacionales/senadores-pro-enmienda-se-reunen- a-puertas-cerradas-1579552.html

Abc Color. 2017l, 1 de abril. "EEUU pide transparencia." Recuperado el 28 de mayo de 2018 de http:/ / www.abc.com.py/nacionales / eeuu-revision-transparente-y-abierta-1580102. html.

Abc Color. 2017m, 1 de abril. "El centro amaneció destrozado" Recuperado el 28 de mayo de 2018 de http:/ / www.abc.com.py/nacionales/el-centro-amanece-destrozado-1579889. html

Abc Color. 2017n, 1 de abril. "'Ellos entraron a matar en el Directorio', dice testigo" Recuperado el 28 de mayo de 2018 de http:/ / www.abc.com.py/nacionales/entraron-a-mataren-el- directorio-1579900.html

Abc Color. 2017o, 1 de abril. "México expresa 'firme rechazo' a violencia en Paraguay." Recuperado el 28 de mayo de 2018 de http://www.abc.com.py/internacionales/mexicoexpresa-firme-rechazo-a-violencia-en-paraguay-1579870.html

Abc Color. 2017p, 2 de abril. "OEA pide paz en Paraguay." Recuperado el 28 de mayo de 2018 de http://www.abc.com.py/internacionales/oea-pide-paz-en-paraguay-1580123. html

Abc Color. 2017q, 17 de abril. "Cartes renuncia a su candidatura." Recuperado el 28 de mayo de 2018 de http://www.abc.com.py/nacionales/no-se-presentara-a-elecciones-1584665.html

Abc Color. 2017r, 27 de abril. "Fin de enmienda que trajo división y muerte al país." Recuperado el 28 de mayo de 2018 de http://www.abc.com.py/edicion-i mpresa/politica/ fin-de-enmienda-que-trajo-division-y-muerte-al-pais-1587998.html

Abc Color. 2017s, 28 de abril. "A Nicanor no le dejaron asumir." Recuperado el 28 de mayo de 2018 de http:/ / www.abc.com.py/edicion-impresa/politica/a-nicanor-no-le-dejaronasumir-1588399.html

Abc Color. 2017t, 21 de diciembre. "Mujeres exigen fin a violencia." Recuperado el 28 de mayo de 2018 de http://www.abc.com.py/nacionales/mujeres-exigen-fin-a-violencia- 1660547.html

Abente Brun, Diego. 2007. "Paraguay en el Umbral del Cambio." Revista de Ciencia Política 27: 221-233.

Abente Brun, Diego. 2008. “Paraguay: ¿Jaque mate?" Revista de Ciencia Política 28 (1): 329- 345.

Abente Brun, Diego. 2012. "Paraguay: Crecimiento económico, conflicto social e incertidumbre política." Revista de Ciencia Política 32 (1): 229-244.

BCP (Banco Central del Paraguay) 2017, 4 de diciembre. "Saldo Bruto de la Deuda Externa." Recuperado el 28 de mayo de 2018 de https: / /www.bcp.gov.py / anexo-estadistico-deuda- externa-trimestral-i380.

Brugnoni, Pablo. 2009. "Paraguay 2008: Estruendosos cambios, silenciosas permanencias." Revista de Ciencia Política 29 (2): 565-590.

Código Electoral. 1996. Recuperado el 28 de mayo de 2018 de https:/ /www.oas.org/es/sap/ $\mathrm{deco} / \mathrm{moe} /$ Paraguay2013/docs/CODIGO_ELECTORAL.pdf.

Constitución Nacional. 1992. Recuperado el 28 de mayo de 2018 de https://www.oas.org/ juridico/spanish/par_res3.htm.

DGEEC (Dirección General de Encuestas Estadísticas y Censos). 2018, marzo. "Principales Resultados de Pobreza y Distribución del Ingreso." Recuperado el 28 de mayo de 2018 de http://www.dgeec.gov.py/Publicaciones/Biblioteca/pobreza/Boletin \%20de $\% 20$ pobreza\% 202017.pdf.

Duarte Recalde, Liliana Rocío. 2013. "Paraguay: Interrupción al proceso de consolidación de la democracia." Revista de Ciencia Politica 33 (1): 303-324.

Gallagher, Michael y Paul Mitchell. 2005. The Politics of Electoral Systems. Oxford: Oxford University Press.

González Bozzolasco, Ignacio. 2017. "Paraguay: La reelección presidencial y los inicios de la carrera electoral 2018." Revista de Ciencia Política 37 (2): 543-562. 
La Nación. 2017, 18 de septiembre. "PLRA desconvocó a internas para la vicepresidencia y otros cargos." Recuperado el 28 de mayo de 2018 de https://www.lanacion.com.py/ politica/2017/09/18/plra-desconvoco-a-internas-para-la- vicepresidencia-y-otros-cargos /

Martínez, Ofelia. 2007. Normativa Electoral Paraguaya. Asunción: DECIDAMOS.

SET (Subsecretaría de Estado de Tributación). 2017. "Presión Tributaria." Recuperado el 28 de mayo de 2018 de http:/ / www.set.gov.py/portal/PARAGUAY-SET/detail?folder- id=repository:collaboration:/sites/PARAGUAY- SET/categories/SET/Estadistica/recaudaciones-tributarias\&content- id=/repository/collaboration/sites/PARAGUAY- SET/documents/estadistica/recaudaciones-tributarias/presion-tributaria-2010-2017.pdf

SET (Subsecretaría de Estado de Tributación). 2018. "Recaudación por Impuestos." Recuperado el 28 de mayo de 2018 de http://www.set.gov.py/portal/PARAGUAY-SET/ detail?folder- id=repository:collaboration:/sites/PARAGUAY- SET/categories/SET/ Estadistica/recaudaciones-tributarias\&content- id=/repository/collaboration/sites/ PARAGUAY- SET/documents/estadistica/recaudaciones- tributarias/2016/diciembre/Recaudacion\%20por\%20Impuestos.pdf

TEI (Tribunal Electoral Independiente). 2017, 17 de diciembre. "Elecciones internas partidarias 2017." Recuperado el 28 de mayo de 2018 de http://tsje.gov.py/static/ups/ docs/archivos/2017/noviembre/listas_candidaturas_plra.pdf.

TEP (Tribunal Electoral Partidario). 2018, 15 de enero. "Resolución por la que oficializan resultados obtenidos y se proclaman a los candidatos electos de la Asociación Nacional Republicana." Recuperado el 28 de mayo de 2018 de http://www.anr.org.py/tribunal_partidario.php.

TSJE (Tribunal Superior de Justicia Electoral). 2018, 22 de abril. "Elecciones generales 2018." Recuperado el 28 de mayo de 2018 de http://tsje.gov.py/eleccionesgenerales-2018. html.

Turner, Brian. 2010. "Paraguay: Muchas novedades y poco cambio." Revista de Ciencia Política 30 (2): 439-450.

Turner, Brian. 2014. "Paraguay: La vuelta del Partido Colorado al poder." Revista de Ciencia Política 34 (1): 249-266.

Última Hora. 2012, 9 de mayo. "Alegre sostiene que si Llano no reconoce derrota en urnas delivery PLRA llegará dividido a 2013." Recuperado el 28 de mayo de 2018 de http:/ / www.ultimahora.com/alegre-sostiene-que-si-llano-no-reconoce-derrota-urnas- delivery-plra-llegara-dividido-2013-n526548.html.

Última Hora. 2015, 23 de agosto. "Pedro Alliana dobló en votos a Marito Abdo en ocho departamentos del país." Recuperado el 28 de mayo de 2018 de http:/ /www.ultimahora. com/pedro-alliana-doblovotos-marito-abdo-ocho-departamentos- del-pais-n924271. html.

Última Hora. 2016, 29 de octubre. "Peña se afilia al Partido Colorado para seguir como ministro." Recuperado el 28 de mayo de 2018 de http:/ / www.ultimahora.com/pena-seafilia-al-partido-colorado-seguir-como-ministro-n1035532.html.

Última Hora. 2017a, 1 de febrero. "Presidente del Congreso asegura que no existen motivos para sacarlo del cargo." Recuperado el 28 de mayo de 2018 de http://www.ultimahora.com/presidente-del-congreso-asegura-que-no-existen-motivos- sacarlo-del-cargo-n1059718.html

Última Hora. 2017b, 31 de marzo. "Momento en que antimotines disparan al diputado Édgar Acosta." Recuperado el 28 de mayo de 2018 de http://www.ultimahora.com/ momento- que-antimotines-disparan-al-diputado-edgar-acosta-n1074793.html

Última Hora. 2017c, 2 de abril. "Cartes destituyó a su ministro del Interior y nombró nuevo comandante." Recuperado el 28 de mayo de 2018 de http:/ /www.ultimahora.com/cartesdestituyo- suministro-del-interior-y-nombro-nuevo-comandante-n1075056.html.

Última Hora. 2017d, 3 de abril. "La CIDH urge a Paraguay a investigar la muerte de un opositor y violencia en protestas." Recuperado el 28 de mayo de 2018 de http:/ /www. ultimahora.com/la-cidh-urge-paraguay-investigar-la-muerte-un-opositor-y- violencia-protestas-n1075438.html 
Última Hora. 2017e, 3 de abril. “Uruguay expresa 'mucha preocupación' ante sucesos violentos en Paraguay." Recuperado el 28 de mayo de 2018 de http://www.ultimahora. com/uruguay-expresa-muchapreocupacion-sucesos-violentos- paraguay-n1075431. html.

Última Hora. 2017f, 5 de junio. “¿Quién es Lea Giménez, la primera ministra de Hacienda de la historia del país?" Recuperado el 28 de mayo de 2018 de http:/ /www.ultimahora. com/quien-es-lea-gimenez-la-primera-ministra-hacienda-la- historia-del-pais-n1089496. html.

Última Hora. 2017g, 12 de julio. "Diputados se aprestan a postergar de nuevo la Ley de Financiamiento Político." Recuperado el 28 de mayo de 2018 de http://www.ultimahora. com/diputados-se-aprestan-postergar-nuevo-la-ley- financiamiento-politico-n1095955.html.

Última Hora. 2017h, 3 de agosto. "Sancionan subsidio para campesinos y el cartismo pierde la pulseada." Recuperado el 28 de mayo de 2018 de http://www.ultimahora.com/ sancionan- subsidio-campesinosy-el-cartismo-pierde-la-pulseada-n1099988.html.

Última Hora. 2017i, 4 de agosto. "Cartes veta subsidio a las deudas de campesinos." Recuperado el 28 de mayo de 2018 de http:/ / www.ultimahora.com/cartes-veta-subsidiolas-deudas-campesinos-n1100305.html.

Última Hora. 2017j, 21 de agosto. "Sin control en internas, los políticos logran blindar cuentas de campaña." Recuperado el 28 de mayo de 2018 de http://www.ultimahora.com/ sin- control-internas-lospoliticos-logran-blindar-cuentas-campana-n1103198.html.

Última Hora. 2017k, 31 de octubre. "Santiago Peña no sabe cuánto gasta en su campaña ni quién lo financia." Recuperado el 28 de mayo de 2018 de http://www.ultimahora. com/santiago-pena-no-sabe-cuantogasta-su-campana-ni-quien-lo- financia-n1115839. html.

Última Hora. 2017l, 1 de noviembre. "Colorado Añetete tampoco conoce el gasto total de su campaña electoral." Recuperado el 28 de mayo de 2018 de http://www.ultimahora.com/colorado-anetete-tampococonoce-el-gasto-total-su-campana- electoral-n1115972.html.

Última Hora. 2017m, 10 de noviembre. "Llamativa ausencia de González Daher en sesión del Senado." Recuperado el 28 de mayo de 2018 de http:/ / www.ultimahora.com/llamativa- ausencia-gonzalez-dahersesion-del-senado-n1118300.html.

Última Hora. 2017n, 22 de diciembre. "Histórico: Senado destituye a Óscar González Daher." Recuperado el 28 de mayo de 2018 de http://www.ultimahora.com/historico-senado- destituye-oscar-gonzalezdaher-n1125228.html.

Última Hora. 2017o, 27 de diciembre. “Oviedo Matto se salva de expulsión gracias a maniobras en el Senado." Recuperado el 28 de mayo de 2018 de http:/ /www.ultimahora. com/oviedo-matto-se-salva-expulsion-gracias-maniobras-el- senado-n1125841.html.

Última Hora. 2018, 8 de marzo. "Senadores aprueban ley de paridad y mujeres celebran." Recuperado el 28 de mayo de 2018 de http://www.ultimahora.com/senadores-aprueban- ley-paridad-y-mujeres-celebran-n1137155.html.

Andrés Carrizosa actualmente está cursando el Doctorado de Ciencia Política de Rice University. Anteriormente recibió una Maestría en Ciencia Política por parte de la Universidad de Salamanca y la Universidad de Columbia del Paraguay. Hizo su carrera de grado en la University of Kansas (KU) titulándose en las carreras de Ciencia Política y Periodismo. Fue miembro fundador de la Asociación de Ciencia Política del Paraguay (ACIPP), y anteriormente fue Secretario del Comité Ejecutivo de la misma. Email: acarrizosa@rice.edu 